ЄРІЦЯН Б.Х., старший викладач, ЛЮБАРСЬКИЙ Б.Г., д.т.н., професор кафедри електричного транспорту та тепловозобудування,

ЯКУНІН Д.І., к.т.н., доцент кафедри електричного транспорту та тепловозобудування (Національний технічний університет «Харківський політехнічний інститут»)

\title{
Задача аналізу оптимізації геометричних розмірів лінійного двигуна нахилу кузова швидкісного електрорухомого складу
}

Введено поняття навантажувальної характеристики, як залежності сили, потрібної для нахилу кузова на заданий кут, від робочого зазору лінійного двигуна. Досліджено природу та закономірність зміни цієї сили. Отримана апроксимована залежність иієї характеристики. 3 метою полегшення обчислень, запропоновано спрощену математичну модель лінійного двигуна для визначення електромагнітної сили, щуо базується на спрощеному вирішенні рівняння щзодо електромагнітної сили лінійного двигуна. Підтверджено адекватність запропонованої спрощеної математичної моделі иляхом порівняння результатів обчислення електромагнітної сили з результатами ї̈ визначення внаслідок розрахунку магнітного поля лінійного двигуна методом кінцевих елементів. Максимальне відхилення спрощеної моделі становить 6,08\%.

Ключові слова: лінійний двигун, прямоходова схема перетворювача, електромагнітна сила, оптимізація.

\begin{abstract}
Актуальність роботи
Вельми важливими критеріями ефективності роботи міжміського пасажирського транспорту $\epsilon$ швидкість i пропускна здатність. На залізницях передових в технічному відношенні країн їх вдалося істотно підвищити, запровадивши високошвидкісний електричний транспорт[1 - 5].

Підвищення швидкості руху можна здійснити двома основними шляхами. По-перше, можна відмовитися від використання кривих порівняно малого радіусу. По-друге, можна залишити в експлуатації існуючу мережу залізниць, вживши заходів по зміні конструкції рухомого складу, що дозволяють підвищити швидкість проходження кривих за рахунок впровадження систем нахилу кузовів [6]. Такий шлях представляється менш витратним, оскільки вводити новий рухомий склад можна поступово, витісняючи існуючий у міру його фізичного та морального зносу $[1,4,5]$.
\end{abstract}

\section{Матеріал і результати досліджень \\ В якості силового приводу систем нахилу кузовів швидкісних поїздів використовуються гідравлічні, пневматичні і електромеханічні системи. Гідравлічна система залежить від погодних умов, екологічно недосконала через можливість витоків, ії конструкція, експлуатація та ремонт відносно складні; пневматична система не забезпечує належної швидкодії; електромеханічна система, будучи найбільш}

( Б.Х. Єріцян, Б.Г. Любарський, Д.І. Якунін, 2015 перспективною, не забезпечує належного рівня безпеки руху через відсутність самоповернення механізму нахилу. [1 - 5]

Усунути зазначені недоліки електромеханічного приводу представляється можливим шляхом використання силового приводу на базі лінійного електродвигуна [1 - 5]. Геометричні та електромагнітні параметри лінійного двигуна можуть змінюватись у широкому діапазоні. Тому для їх вибору необхідно застосовувати методи оптимального проектування, основною частиною яких є задача аналізу, що визначає цільову функцію.

Мета роботи - розробити задачу аналізу для оптимізації геометричних розмірів лінійного двигуна, виходячи із його функціональних можливостей, щодо забезпечення нахилу кузова на різний максимальний кут при обраній геометрії та кінематиці механізму нахилу.

\begin{tabular}{l}
\hline Викладення основного матеріалу \\
\hline У $[1]$ доведено принципову можливість \\
використання лінійного двигуна для нахилу кузову \\
швидкісного потяга. Проте, геометричні параметри \\
задіяного лінійного двигуна обиралися найбільшими 3 \\
можливих за умов компонування у візку рейкового \\
транспортного засобу - задля досягнення \\
якнайбільшого зусилля на якорі лінійного двигуна. \\
Так, діаметр корпусу двигуна за умов компонування не \\
має бути більшим 0,5 м у діаметрі та 0,4 м завдовжки. \\
У [7] показано, що максимальний кут нахилу $8^{\circ}$ не \\
$\epsilon \quad$ актуальний для залізниць України. Також
\end{tabular}


враховуючи, що тестова задача у [1] вирішувалася для граничного кута нахилу $\theta=7^{\circ}$, таке саме значення у подальшому також обрано за граничне.

Також враховано неможливість прямого використання електромагнітного лінійного двигуна для приводу нахилу кузова через обставини, які пояснює рис. 1 .

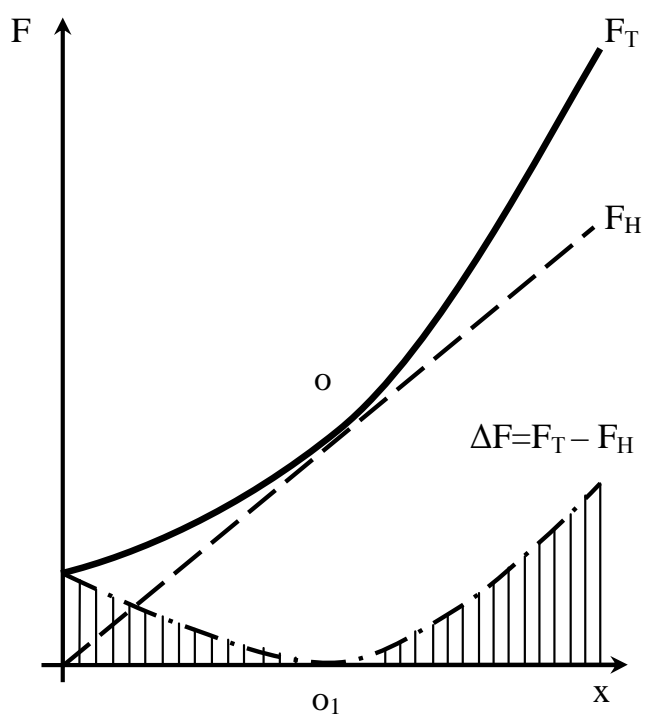

Рис. 1. Тягова $\mathrm{F}_{\mathrm{T}}$ i навантажувальна $\mathrm{F}_{\mathrm{H}}$ характеристики

Тут наочна невідповідність тягової характеристики навантажувальній. Якщо друга носить практично прямолінійний характер, то перша при незмінному значенні магніторушійної сили (МРС) є гіперболою. Для забезпечення працездатності пристрою в цілому необхідно, щоб тягова характеристика по силі, що реалізується, перевершувала навантаження, в межі наближаючись до неї тільки в точці $o$ (назвемо іiі критичною).

Безперечно, привести у відповідність градієнт силової і навантажувальної характеристик можна лише застосовуючи схему регулювання МРС, тобто забезпечуючи живлення лінійного двигуна постійним струмом змінюваної величини. Цим умовам задовольняють джерела живлення, зібрані на базі напівпровідникових перетворювачів, за схемами імпульсного регулятора, прямоходового або мостового перетворювачів.

Перевагою імпульсного регулятора $\epsilon$ простота конструкції, обумовлена наявністю тільки одного ключа. Проте робота регулятора при навантаженні такого роду викликає в його елементній базі перенапруження при комутації.

У схемах мостового i прямоходового перетворювачів напруга, що виникає при комутації, значно нижче. Перевагою схеми мостового інвертора $є$ те, що вона дозволяє підвищити крутизну заднього фронту кривої імпульсу струму за рахунок реверсного включення напруги на навантаженні, що прискорює процес комутації. Недолік - наявність чотирьох ключів.

Прямоходова схема перетворювача, так само, як i мостова, характеризується низькими перенапруженнями при комутації, проте в ній, на відміну від мостової, використовуються тільки два ключі. Тому для живлення електромагнітного двигуна в приводі нахилу кузова раціональне використання саме прямоходової схеми.

Енергія, що ії̈ перетворює ЛД, може бути знайдена з виразу

$W_{E M}=\int_{x_{n o y}}^{x_{\max }} F_{T} d x$

Енергія, що потрібна для нахилу кузова, може бути знайдена з виразу

$W_{H}=\int_{x_{n o y}}^{x_{\max }} F_{H} d x$

Кінетична енергія системи дорівнює нулю на початку та наприкінці процесу повороту кузова, адже швидкість повертання кузова у цих точках є нульовою. Тому різниця між енергією, що перетворює ЛД $W_{\mathrm{EM}}$ та енергією, котра потрібна для нахилу кузова $W_{\mathrm{H}} \epsilon$ енергією втрат $\Delta W$, зумовлених невідповідністю тягової та навантажувальної характеристик

$\Delta W=W_{E M}-W_{H}$

Нами поставлено задачу оптимізації геометричних розмірів лінійного двигуна, виходячи із його функції забезпечення нахилу кузова на різний максимальний кут при обраній геометрії та кінематиці виконавчої частини механізму нахилу. Метою оптимізації $\epsilon$ мінімізація енергії втрат $\Delta W$. Умовні позначення геометричних показників ЛД обраної схеми наведено на рис. 2.

У роботі $[1,2]$ тягову характеристику лінійного двигуна отримано розрахунком магнітного поля за методом кінцевих елементів. Такий підхід е вельми точним, проте дуже затратним у часі, адже потребує численних розрахунків поля при різному положенні якоря лінійного двигуна. Щоб позбутися вказаного недоліку, у цій роботі пропонується спрощена методика розрахунку сили лінійного двигуна. 


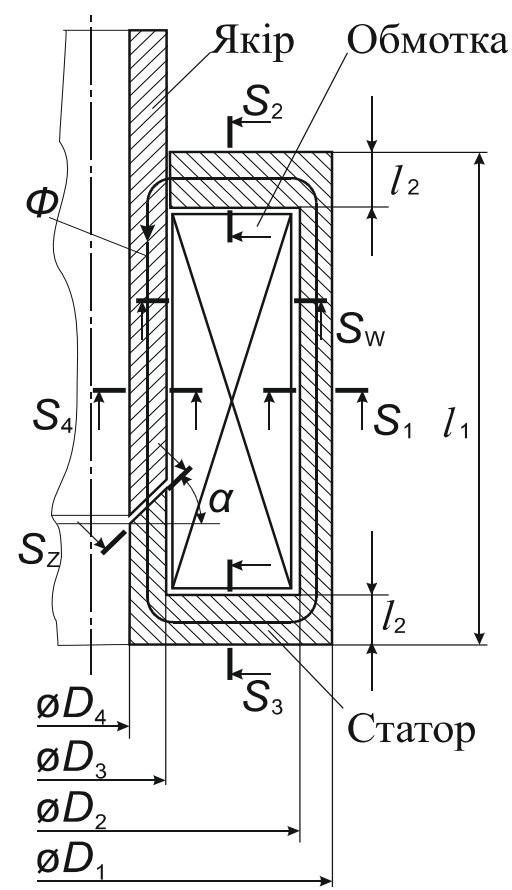

Рис. 2. Схема досліджуваного лінійного двигуна

Для розрахунку сили $F_{T}$ використовувався енергетичний підхід. Внесемо припущення: перетворення енергії відбувається у повітряному зазорі, насичення матеріалу статора та якоря не має, а також немає розсіювання потоків у магнітопроводі. Відповідно до цього підходу маємо

$$
F_{T}=-\frac{\partial W}{\partial x}
$$

де $W$ - енергія магнітного поля.

$$
\begin{aligned}
& W=\int_{0}^{I} \psi \cdot d i=\int_{0}^{I} B \cdot S_{z} \cdot d i=\int_{0}^{I} \mu_{0} \cdot H \cdot S_{z} \cdot d i= \\
& =\int_{0}^{I} \mu_{0} \cdot \frac{i}{x} \cdot S_{z} \cdot d i=\frac{\mu_{0} \cdot S_{z}}{x} \frac{I^{2}}{2}=\frac{\mu_{0}}{2} \frac{I^{2}}{x} S_{z}
\end{aligned}
$$

де $\psi$ - потокозчеплення, $I$ - МРС обмотки ЛД, $B$ магнітна індукція у повітряному зазорі, $S_{Z}-$ площа перетину, $\mu_{0}-$ магнітна проникність повітря, $H$ - напруженість поля у повітряному зазорі.

Таким чином,

$$
F_{T}=\frac{\mu_{0}}{2} \frac{I^{2}}{x^{2}} S_{z},
$$

$F_{T}=\left(\frac{\mu_{0}}{2} \kappa_{3}^{2} J^{2}\right) \frac{S_{W}^{2}}{x^{2}} S_{4}$,

де $\kappa_{3}-$ коефіцієнт заповнення обмотки статора ЛД, $J$ щільність струму обмотки статора ЛД, $S_{\mathrm{W}}$ - площа обмотки статора ЛД, $S_{4}$ - площа перетину осердя якоря.

Таким чином (7) $\epsilon$ спрощеною математичною моделлю ЛД для визначення електромагнітної сили.

Для підтвердження адекватності запропонованої спрощеної математичної моделі пропонується провести шляхом порівняння результатів обчислення електромагнітної сили 3 результатами іiі визначення внаслідок розрахунку магнітного поля ЛД методом кінцевих елементів.

Розрахунок магнітного поля методом кінцевих елементів проведено за допомогою програмного комплексу FEMM [1, 2, 8], який апробовано у низці наукових досліджень різними авторами, у тому числі й для ЛД [1,2 ]

Постанова задачі розрахунку магнітного поля

Підтвердження адекватності спрощеної математичної моделі раціонально проводити у найбільш напруженому режимі роботи приводу нахилу критичний та близькі до нього режими при максимальному куті нахилу $7^{\circ}$ (див. рис. 1точка «о»).

Постанова задачі розрахунку магнітного поля методом кінцевих елементів в аксіально-симетричній формі. Це можливо тому що ЛД має вісь симетрії, що співпадає з віссю якоря. Для обмеження розрахункової зони введена додаткова сферична поверхня, яка при постановці задачі виражена півколом. Розрахунки проведено за допомогою методик наведених в[8].

\section{Результати розрахунку магнітного поля}

Далі у роботі були проведені розрахунки магнітного поля для повітряних зазорів $N$ в інтервалі від 60 до 80 мм. Картини магнітних полів приведені на рис. 3 За методикою [8] було розраховано електромагнітні сили, залежності яких від ходу якоря наведені на рис. 6 з використання тензору напружень Максвела. Остаточно, сумарна сила визначається за рахунок інтегрування диференційної сили за контуром навкруги якоря.

Для порівняльного аналізу на рис. 4 приведено графік електромагнітної сили, визначений за допомогою спрощеної математичної моделі (7). 


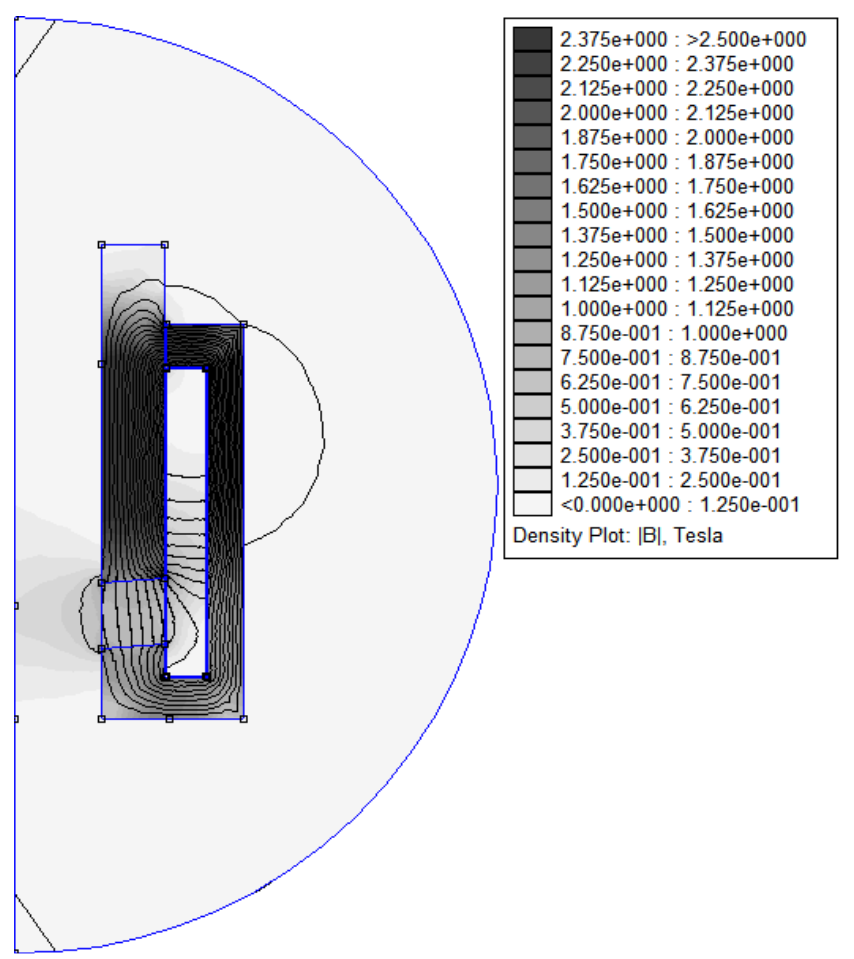

Рис. 3. Картина магнітного поля ЛД при робочому зазорі 70 мм та МДС якоря 71500 А.

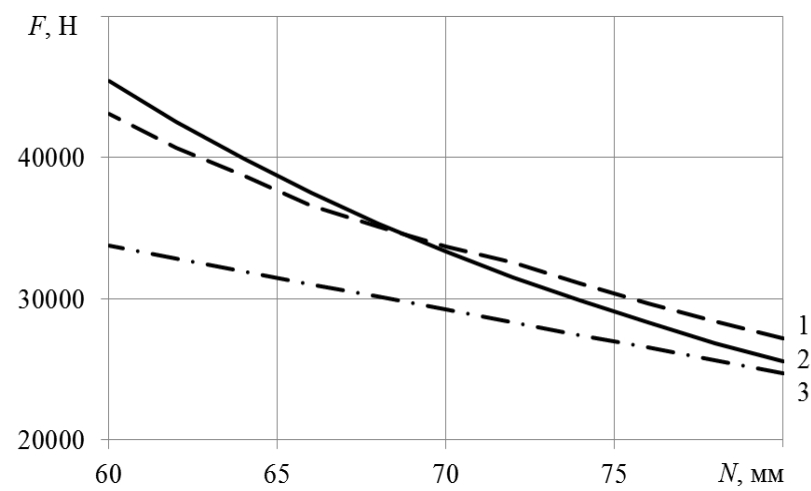

Рис. 4. Залежність сил, що діють на якір ЛД від робочого зазору:

1 - тягова характеристика, розрахована по МКЕ; 2 - тягова характеристика, розрахована по спрощеної методиці;

3 - навантажувальна характеристика.

Як бачимо з рисунку, наявне добре співпадіння результатів розрахунків за спрощеною методикою та шляхом моделювання магнітного поля лінійного двигуна за методом кінцевих елементів. Максимальне відхилення спрощеної моделі становить 6,08\%, що допустимо для розглянутого класу розрахунків та підтверджує адекватність розробленої моделі.

Отже, запропонована методика $є$ прийнятною та може бути використана у подальшому дослідженні.

\section{Висновки}

1. Введено поняття навантажувальної

характеристики, як залежності сили, потрібної для нахилу кузова на заданий кут, від робочого зазору лінійного двигуна. Отримана апроксимована залежність цієї характеристики.

2. 3 метою полегшення обчислень, запропоновано спрощену математичну модель лінійного двигуна для визначення електромагнітної сили, що базується на спрощеному вирішенні рівняння щодо електромагнітної сили лінійного двигуна.

3. Підтверджено адекватність запропонованої спрощеної математичної моделі шляхом порівняння результатів обчислення електромагнітної сили 3 результатами iї визначення внаслідок розрахунку магнітного поля лінійного двигуна методом кінцевих елементів. Максимальне відхилення спрощеної моделі становить $6,08 \%$.

\section{Література}

1. Д.И. Якунин. Электромеханическая система привода с линейным двигателем для наклона кузовов скоростного подвижного состава. Диссертация на соискание ученой степени кандидата технических наук.- Харьков, 2010, 202 с.

2. Любарський Б. Г. Теоретичні основи для вибору та оцінки перспективних систем електромеханічного перетворення енергії електрорухомого складу. Дисертація на здобуття наукового ступеня доктора технічних наук за спеціальністю 05.22.09. «Електротранспорт». Національний технічний університет «Харківський політехнічний інститут». Харків, - 2014. 368c.

3. Корниенко В.В. Высокоскоростной электрический транспорт. Мировой опыт / В.В. Корниенко, В.И. Омельяненко - Харьков: НТУ «ХПИ», 2007. $159 \mathrm{c}$.

4. Омельяненко В.И. Поезда с наклоняемыми кузовами для скоростного пассажирского движения / В.И. Омельяненко, Г.В.Кривякин, Д.И. Якунин, Е.С. Редченко // Локомотив-информ. - Харьков: Техностандарт, 2008. - №5 С. 12-17.

5. Развитие технологии наклона кузовов вагонов // Железные дороги мира, 2001. - №11.- Режим доступу до журн.: http://css-rzd.ru/zdm/112001/01185-1.htm.

6. Якунин Д.И. Влияние наклона кузова вагона при движении по кривым участкам пути на взаимодействие колес с рельсами / Д.И. Якунин, Ю.В. Макаренко, В.Г. Маслиев // Вісник Дніпропетровського національного університету залізничного транспорту ім. акад. В. Лазаряна.Дніпропетр.: ДНУЗТ ім. акад. В. Лазаряна, 2009.С. 248-251. 
7. Якунин Д.И. Предпосылки для моделирования движения по рельсовому пути экипажа, оборудованного устройствами для наклона кузова / Д.И. Якунин, Е.Ю. Зверев, А.Н. Срибник // Вісник НТУ «ХПІ», 2013.- С.76-80.

8. Finite Element Method Magnetics [Електронний pecypc] - Режим доступу до ресурсу: http://www.femm.info/wiki/HomePage.

Б.Х. Ерицян, Б.Г. Любарский, Д.И. Якунин. Задача анализа оптимизации геометрических размеров линейного двигателя наклона кузова скоростного электроподвижного состава. Введено понятие нагрузочной характеристики, как зависимости силы, необходимой для наклона кузова на заданный угол, от рабочего зазора линейного двигателя. Исследована природа и закономерность изменения этой силы. Получена аппроксимированная зависимость этой характеристики. С целью облегчения вычислений, предложена упрощенная математическая модель линейного двигателя для определения электромагнитной силы, базирующейся на упрощенном решении уравнения по электромагнитной силе линейного двигателя. Подтверждена адекватность предложенной упрощенной математической модели путем сравнения результатов вычисления электромагнитной силы с результатами ее определения по расчету магнитного поля линейного двигателя методом конечных элементов. Максимальное отклонение упрощенной модели составляет 6,08 \%.

Ключевые слова: линейный двигатель, прямоходовая схема преобразователя, электромагнитная сила, оптимизация.

B.Ch. Yeritsyan, B.G. Lyubarskiy, D.I. Iakunin. The task of analyzing geometric dimension optimization of a linear engine of a car body tilt of high-speed electric rolling stock. A notion of a load characteristic, as force dependence, necessary to tilt a car body at a preset angle from operating clearance of a linear engine has been introduced. The nature and regularity of this force change have been studied. Approximate dependence of this characteristic has been obtained. A simplified mathematical model of a linear engine to determine electromagnetic force, based on the simplistic solution of the equation on electromagnetic force of a linear engine has been proposed for the purpose of facilitating the calculations. The adequacy of the proposed simplified mathematical model has been proved by means of comparing the results of calculations of the electromagnetic force with the results of its determination according to the calculation of a linear engine magnetic field by the method of finite elements. Maximal deviation of a simplified model is $6,08 \%$.
Key words: linear engine, forward converter circuit, electromagnetic force, optimization.

Рецензент д.т.н., професор кафедри електричного транспорту та тепловозобудування НТУ «ХПІ» В.Г. Маслієв

Поступила 16.09.20152.

Б. Х. Сріцян, НТУ «ХПІ», стариий викладач кафедри електричного транспорту та тепловозобудування, Харків, Україна, bagish_ericjan@mail.ru.

Б. Г. Любарський, НТУ «ХПI», д.т.н., професор кафедри електричного транспорту та тепловозобудування, Харків, Україна, lboris19111972@mail.ru

Д. І. Якунін, НТУ «ХПI», к.т.н., доцент кафедри електричного транспорту та тепловозобудування, Харків, Україна, unicomber@ukr.net.

B.Ch. Yeritsyan, NTU "KPI", Senior Lecturer of the Department "Electrical transport and diesel locomotive", Kharkiv, Ukraine, bagish_ericjan@mail.ru.

B.G. Lyubarskiy, NTU "KPI", Ph.D., Docent of the Department "Electrical transport and diesel locomotive", Kharkiv, Ukraine, lboris19111972@mail.ru.

D.I. Iakunin, NTU "KPI", Ph.D., Docent of the Department "Electrical transport and diesel locomotive", Kharkiv, Ukraine, unicomber@ukr.net. 